\title{
Drilling behavior of flax/poly(lactic acid) bio-composite laminates: An experimental investigation
}

\begin{abstract}
This paper aims to investigate the effects of machining parameters such as spindle speed, feed rate and drill diameter on machinability of flax/poly(lactic acid) bio-composites, to analyze the relations among cutting forces, drillinginduced damages and crack propagation of the drilled samples. In particular, a set of drilling experiments were conducted using different drilling conditions and a new low-cost measurement set-up was developed to measure the cutting force during the drilling operation. In addition, the analysis of variance (ANOVA) was applied to identify the significance of each individual cutting parameter. The experimental results indicate the relation between the thrust force and the machinability parameters of flax fiber reinforced bio-composite. The increase in spindle speed reduces thrust force and delamination size of the drilled holes, whereas an increase in feed and drill diameter leads to a considerable increase in both thrust force and delamination factor. The effect of spindle speed on peripheral damage was not significant for the drills tested, though the feed rate was found to play the key role on the delamination damage area. The best hole quality was achieved with the samples drilled at spindle speed and feed rate of $3000 \mathrm{rpm}$ and $0.11 \mathrm{~mm} / \mathrm{rev}$, respectively.
\end{abstract}

Keywords: natural fiber reinforced composites, thrust force, delamination, composite, drilling, machinability

\section{Introduction}

Fiber reinforced composites (FRCs) are progressively replacing conventional metallic engineering materials in many industrial and structural uses due to the significant advantages they offer such as low weight, high strength, superior corrosion resistance, and low cost (Mazumder et al. 2016)(Kwon et al. 2014). Comparing with synthetic fibers, natural fiber based composite possess some superior characteristics such as low price, high thermal and acoustic insulation, biodegradability, high specific strength, design flexibility, and no additional $\mathrm{CO}_{2}$ emissions which helps to reduce the effects of climate change and global 
warming (Holbery and Houston 2006)(Alimuzzaman 2013). Of all the natural fibers available, flax fiber has been extensively investigated due to its excellent properties such as resistance to abrasion and wear, biodegradability, durability, high strength to weight ratio, abundance and low cost of production compared to other synthetic fibers. Lut et al. (Pil et al. 2016) recently reviewed that flax fiber bio-composites, exhibit distinctive combinations of technical and non-technical characteristics, which appear to inspire designers of consumer goods to use this fiber.

Several well-known European car manufacturers and suppliers have expressed their interest in utilizing the natural fiber composites in numerous automotive interior and exterior parts (Abdul Nasir, Azmi, and Khalil 2015)(Fan and Njuguna 2016). As a result of a widening range of NFRCs usage in structural and non-structural component applications, these near net-shape composite products still require secondary machining operations to meet the dimensional constraints. Amongst various machining operations, conventional drilling is still considered as the most economical secondary operations for creating holes (Davim, Reis, and António 2004). However, drilling of NFRC is a rather intricate task due to the mechanical anisotropic and inhomogeneous structure, high abrasiveness, and hard reinforced fibers. Several note-worthy problems are related to the machining processes, particularly in drilling, including delamination, fiber peel up, thermal degradation, uncut fiber, fiber pullout, spalling and hole shrinkage (Kavad et al. 2014). Among these, drilling-induced delamination is considered as the most critical damage because of its high level of impact on the quality of the drilled holes as well as their accuracy (Ismail et al. 2016a).

Drilling-induced delamination considerably reduces the mechanical strength, fatigue resistance and the quality of the holes in terms of dimensional and geometrical tolerances. The undesirable damages caused by the drilling process result in lowering strength against fatigue which can be extremely detrimental to the long-term performance of composites. 
Several studies have shown that delamination is basically affected by the choice of the machining variables, cutting tool geometrical parameters (Singh, Bhatnagar, and Viswanath 2008)(sunny, Babu, and Philip 2014), as well as the manufacturing method and the nature of composite laminates (Ho et al. 2012)(Saleem et al. 2013). Turki et al. (Turki et al. 2014) reported that an increase in the feed rate leads to a considerable increase in the delamination factor while the low feed rate creates minor damage on carbon/epoxy composites. Ismail et al. (Ismail et al. 2016b) analysed the effects of cutting parameters and aspect ratios on delamination and surface roughness of hemp fibre reinforced polycaprolactone (HFRP) laminates and compared the results with CFRP composite materials. It has been concluded that the effect of feed rate on delamination and surface roughness increased with the aspect ratio and the size of delamination damage was lower in HFRP laminates in comparison to CFRP composite laminates. For rivets and bolted joints, the efficiency of the joint is highly dependent on the quality of holes. Damage free holes ought to be drilled in the parts to reach precision and high strength (Mazumder et al. 2016). Precise selection of drilling conditions have been a major challenge and great deal of research has managed to study the effects of parameters associated with drilling operation on the properties of drilled composites (Sreenivasulu and Rao 2016).

In this paper, the result of an experimental study on the machinability of the sustainable compression moulded flax fiber/PLA composites considering various cutting conditions are presented. The machinability was defined by the size of delamination at drill entry and exit sides, and surface quality of the drilled holes. The effect of main drilling parameters such as spindle speed, tool diameter and feed rate on the delamination factor and hole quality of the flax fiber bio-composites is evaluated by developing a new measuring system adapted to a drilling machine to record the cutting thrust force during drilling. This 
work is mostly focused on studying the effect of cutting parameters on the drilling thrust force and delamination produced when drilling a NFRC.

\section{Experimental Procedure}

\subsection{Material Preparation}

The composite laminates were fabricated using unidirectional flax fabric as the fiber and Poly(lactic acid) (PLA) as the matrix. The flax fiber was supplied by Lineo Company (France) with an aerial weight of $180 \mathrm{~g} / \mathrm{m}^{2}$ and density of $1.5 \mathrm{~g} / \mathrm{cm}^{3}$. The PLA was $100 \mu \mathrm{m}$ thick and supplied by Magical Film Enterprises Co. Ltd (Taiwan). The average glass transition temperature $(\mathrm{Tg})$ was $70{ }^{\circ} \mathrm{C}$ and the crystalline melting temperature $(\mathrm{Tm})$ was about $150{ }^{\circ} \mathrm{C}$. The flax/PLA composite samples were prepared at room temperature via compression moulding on a lab scale set-up. The orientation of the layers were unidirectional and composite volume fraction was around 50\%. The PLA film was placed on the surface of the bottom mould and it is followed by a single layer of fiber. This pattern was repeated for 30 fiber layers. The platen temperature of the compression moulding machine (Carver Inc, Wabash, USA) was set to $170{ }^{\circ} \mathrm{C}$, moderately above the melting temperature of the PLA. After fabricating the laminates, samples were cut by laser cutting machine to the dimensions $40 \mathrm{~mm} \times 250 \mathrm{~mm} \times 7.5 \mathrm{~mm}$ for drilling experiments. Figure 1 presents the fabrication process of composite specimens.

Tensile testing was carried out based on ASTM D3039/D3039 M using a universal mechanical testing machine (Lloyd Model LR30k 30KN) for the fabricated composite material along the fiber direction. The dimensions of the tensile test specimens were $15 \mathrm{~mm} \times$ $250 \mathrm{~mm}$ and the speed of the crosshead was $2 \mathrm{~mm} / \mathrm{min}$. The measurement results were obtained from an average of five test specimens, with ultimate tensile strength of $238.62 \mathrm{MPa}$ and the Young's modulus of $21.23 \mathrm{GPa}$. The tensile strain in the specimens were measured with a $50 \mathrm{~mm}$ Instron extensometer attached to the in-plane surface of the sample. Three- 
point bending tests were also performed on the same machine with a test span of $60 \mathrm{~mm}$ and a crosshead displacement rate of $2.4 \mathrm{~mm} / \mathrm{min}$. Load displacement curves were obtained from these tests and flexural strength values were determined.

\subsection{Measurement of thrust force}

Drilling thrust force was measured by the use of three piezoelectric ICP force sensors (PCB Type 208C03). These sensors convert the high impedance charge output into a low impedance voltage signal for analysis or recording. Each sensor is provided with a calibrated sensitivity value in $\mathrm{mV} / \mathrm{N}$ from the manufacturer. Experimental set-up details are depicted in Figure 2. The thrust force results were acquired using a NI DAQ card and LabVIEW ${ }^{\circledR}$ software into a PC for further analysis. When a force is applied, each sensor converts the load share on it into a measurable voltage signal in respect to its sensitivity, thus the total value of all sensors defines the total load applied. The main advantages of new measurement set-up are low cost, configurability and flexibility. In order to conduct experiments, a holding fixture has been designed and fabricated to clamp composite specimens to the force sensors as presented in Figure 3.

\subsection{Delamination assessment}

Delamination assessment in NFRC materials is a rather a challenging task, especially for dark fiber reinforced composites since their color makes the visual inspection difficult. In the present work, a universal OLYMPUS BX 40X optical microscope was utilized to measure the delamination damage in the area of the drilled holes. The one dimensional delamination factor $\left(\mathrm{F}_{\mathrm{d}}\right)$ is described as the ratio of the maximum diameter of the observed delamination $\left(D_{\max }\right)$ to the nominal diameter of the drill hole $\left(D_{\text {nom }}\right)$, as shown in Figure 4 (Chen 1997)(Hocheng and Tsao 2005). Accordingly, an increase in value of the delamination factor indicates that the delamination effect is also increasing (Tsao and Hocheng 2004). The delamination factor value can be calculated using following equation: 
Delamination Factor $\left(F_{d}\right)=\frac{D_{\max }}{D_{\text {nom }}}$

\subsection{Drilling experiment}

The experiments were conducted on the MultiCam M1212 CNC vertical machining centre. The force sensors were mounted on the fixture and the drilling fixture was clamped on the machine table. The data collected were transferred to a computer for further analysis. The experimental setup employed for conducting the drilling is presented in Figure 5.

In order to study the machinability of the fabricated NFRC (Flax/PLA) and investigate the effects of machining parameters on cutting force signals and the quality of the drilled holes, a series of experiments are conducted. All specimens were drilled using two types of high speed two-fluted standard twist drills with $118^{\circ}$ point angle. The tool diameters are $8 \mathrm{~mm}$ and $4 \mathrm{~mm}$, respectively. The details are presented in Table 1 . The experiments were conducted on $\mathrm{CNC}$ drilling machine without coolant. The values for experiments were selected based on the literature review and drilling machine specifications. The selected cutting parameters for drilling of the fabricated composite are illustrated in Table 2.

The influence of several main process parameters including spindle speed, feed rate and drill diameter has been investigated while the others are kept constant. The drilling process was programmed into the $\mathrm{CNC}$ machine for a continuous operation based on the experimental plan. Observations were made instantly after finishing the experimental work in the laboratory.

\section{Results and discussion}

Figure 6 illustrates the influence of spindle speed, drill diameter and feed on the cutting force while drilling flax fiber reinforced composites for both $8 \mathrm{~mm}$ and $4 \mathrm{~mm}$ diameter drills. As shown in the figure, increasing the feed rate leads to a noticeable increase in drilling thrust force mainly due to the elevation in the shear area. At higher feed rates, the self-generated feed angle increases considerably and results in reducing the effective clearance angle. 
Reduction in effective clearance angle makes rubbing against the composite substance and thus, leads to a higher value of thrust force (Velayudham and Krishnamurthy 2007).

Moreover, based on the experimental results, it is noticed that the thrust force is affected by spindle speed within the tested range. The value of thrust force decreased by 42 and 35 percent when spindle speed was raised from $300 \mathrm{rpm}$ to $3000 \mathrm{rpm}$ at the constant feed rate of $(0.01 \mathrm{~mm} / \mathrm{rev})$ for samples drilled with 8 and $4 \mathrm{~mm}$ drills, respectively. This conclusion agrees with the results of many researchers (Abrão et al. 2008)(Rawat and Attia 2009).

Besides the effect of feed and spindle speed, a clear rise in the value of thrust force was seen with an increase in drill diameter for all drilling speeds. This can be attributed to the fact that higher shear force is needed for removing the material from the hole. The lowest thrust force $(18 \mathrm{~N})$ was measured for sample 10 which was drilled with $4 \mathrm{~mm}$ dill diameter, at the highest spindle speed and lowest feed rate. In addition, in a similar drilling condition, the thrust force was increased by 67 percent when drill diameter increased to $8 \mathrm{~mm}$. The increase of the cross-sectional area of the undeformed chip which in turn elevates the chip formation resistance was found to be the main reason for increasing the value of thrust force with increasing feed rate and diameter of drill (Khashaba et al. 2010).

Observations on thrust force indicate a change in variation at $0.11 \mathrm{~mm} / \mathrm{rev}$ feed rate which appears to be the critical value of the feed in drilling this composite material. Delamination damage is basically related to the inter-ply failure phenomenon induced by an exterior force, such as drilling, which leads to separation of the plies of reinforcement. There exists two discernible delamination mechanisms related to drilling of FRCs known as peel-up delamination, which appears at the entrance side of the drilled holes periphery and pushdown delamination, which occurs near the periphery of drill exit. Natural fibers, such as flax, react differently to the applied thrust force in comparison to that of synthetic fibers. This can be attributed to the soft nature of natural fibers, mainly due to their high cellulose content. 
Therefore, the energy can greatly be dissipated through fiber deformation when in a contact with a solid drilling tool (Chegdani et al. 2015). This feature enables the natural fibers to deform under the interaction with a cutting tool and limit failure because of the brittle fracture of the fiber (Nirmal, Low, and Hashim 2012). Table 3 qualitatively shows the images of drilling-induced delamination damage for all the samples drilled at different drilling conditions. The delamination factor at drill entrance was determined according to Eq. (1) and summarised in the Table 3. The results of these captured images indicate that the push down for almost all the samples were marginally more extensive than that of associated with peelup delamination.

After completing the drilling tests, in order to investigate the tool wear, observations were made on the cutting lips and chisel edge of the utilized drill bits. As can be seen in Figure 7, almost no wear was observed in the flank surface and the cutting edges of the used drills. Moreover, with the increase in the number of drilled holes, no considerable increase was noticed in the cutting thrust force. This can be attributed to the soft structural nature of the fabricated NFRC (FF/PLA) when compared to other synthetic fiber reinforced composites. Accordingly, longer tool life in expected when drilling NFRCs with respect to the number of holes.

The quality of the drilled holes, particularly in terms of delamination, has been shown to be strongly dependent on the input parameters used in this research. The results of delamination factors of the drilled samples indicate that drilling-induced delamination increased with increasing the feed rate, and diameter of the drill, and decreased when the spindle speed increased. This is predominantly due to the increase in thrust force when drilling composite laminates. Thrust force is considered as the major cause of delamination, hence below the critical thrust force no peripheral damage appears around the drilled hole. Therefore, delamination basically results from the extreme thrust force during drilling 
processes (Hocheng and Tsao 2005). Analysis of delamination mechanisms in order to find the critical thrust force during drilling using Linear Elastic Fracture Mechanics (LEFMs) methodology have been developed and various analytical models have been proposed. Hocheng and Dharan (Ho-Cheng and Dharan 1990) developed the most commonly used delamination model to determine critical thrust force at the onset of delamination for twist drill that can be calculated as:

$F_{c r i t}=\pi\left[\frac{8 G_{I C} E h^{3}}{3\left(1-v^{2}\right)}\right]^{1 / 2}=\pi \sqrt{32 G_{I C} M}$

where $M=E h^{3} / 12\left(1-v^{2}\right)$ is the stiffness per unit width of the fiber reinforced composite, $G_{I C}$ is the critical crack propagation energy in mode I per unit area, $h$ is the uncut thickness under cutting tool, $E$ is Young's modulus in fiber direction, $v$ is Poisson's ratio for the material.

Accordingly, in order to avoid onset of delamination damage, the applied thrust force must not exceed the critical value, which is dependent on the composite properties and the thickness of uncut-plies under the cutting tool. The theoretical prediction of the critical thrust force for the used composite material is $36.4 \mathrm{~N}$, which is found to be close to the experimental measurements. It should be mentioned that a simplification has been made in this model as the highest $E$ is used overall for the adopted isotropic calculation instead of applying a complicated algorithm for the anisotropic case.

A correlation exists between the thrust force and delamination, hence reducing thrust force in drilling of FRCs through optimizing cutting variables may be one of key approaches for overcoming delamination damage (Faraz, Biermann, and Weinert 2009).

The results of delamination factors presented in Table 3, illustrated samples with higher trust force values had a higher delamination damage area. As can be seen, the samples 9 and 18 have the highest values of delamination factor amongst all the samples. This can be 
attributed to their high values of cutting thrust force recorded during the drilling. These samples were drilled at the minimum spindle speed and maximum feed rate with two different drill diameters. When drilling at a high feed rate, the drill bit point behaves as a punch that extrudes the material and pierces the composite laminate. This can be due to the negative rake angle of some sections on the twist drill point which mostly extrude the material, rather than cut them through. The piercing action of the cutting tool results in a considerable push-down delamination along with fiber pull out and matrix debonding regardless of drilling thrust force values as can be seen in samples 9, 12 and 18 shown in Table 3. Moreover, at high feed, in addition to the delamination, tearing a part of ply which carries the small uncut fibers with it causes a spalling defect (Turki et al. 2014).

Another machining parameter that determines the efficiency of a drilling operation is the material removal rate (MRR). The rate of evacuating chips in the drilling operation is strongly related to the cutting parameters. Selecting the cutting parameters to achieve both high material removal rate and high quality is quite difficult. MRR has a significant influence on the effectiveness, rate and cost of production. The rate of the composite removal for all the drilling conditions has been calculated using the standard equation as stated below (Pradeep Kumar J. 2012) and the results obtained for both 4 and $8 \mathrm{~mm}$ drill diameters are presented in Table 3.

Material Removal Rate $\left(\mathrm{mm}^{3} / \mathrm{min}\right)=\frac{\pi D^{2} f N}{4}$

where, MRR is material removal rate, $D$ is drill diameter in $\mathrm{mm}, f$ is feed rate in $\mathrm{mm} / \mathrm{rev}, N$ is spindle speed in rpm. As can be seen, MRR has a direct relationship with spindle speed, drill diameter, and feed rate. Therefore, increase in these variables led to an increase in MRR which in turn, increased the delamination factor for almost all the samples.

For further analysis and interpretation of results, a statistically based technique known as analysis of variance (ANOVA) was applied to evaluate the relative importance of the 
different drilling parameters and to estimate the errors of experimental process. The main objective of using ANOVA is to investigate which cutting parameter has the most effect on the response. The results of ANOVA for thrust force during the drilling process using Minitab 16 statistical software and $95.0 \%$ confidence interval is presented in Table 4. Moreover, a Pareto chart was used to find the percentage of the contribution of each parameter to the thrust force. Pareto chart is a type of chart in which individual values are represented in descending order from largest to smallest by bars, and the cumulative percentage total is represented by a line. The pareto chart for the investigated cutting parameters is shown in Figure 8.

According to the results of Table 4 and Figure 8, thrust force during the drilling process is significantly affected by feed rate $(82 \%)$ followed by the spindle speed $(9 \%)$ and drill diameter $(7 \%)$. The term of error shown in the figure represents the experimental errors as well as the effect of parameters not included in the experiments and their interactions. It is known that the smaller the p-value, the higher the significance of the factor. According to the table and based on P-value column, the feed rate has a greater statistically percentage of contribution and considerably affects the drilling thrust force while the effect of other parameters are less significant. These results agree closely with the graphical results of experiment presented in Figure 6.

It has been shown that the effect of spindle speed on the peripheral damage was not profound, while feed rate was found to play the key role on the responses such as the thrust force and the delamination damage area. However, it should be mentioned that high spindle speed (especially when combined by low feed rate) generates excessive heat which can soften the composite material and melt the polymer matrix of composite and thus increases the delamination damage significantly as it is noticed in samples 1 , and 10, drilled at high spindle speed of $3000 \mathrm{rpm}$. The delamination factor of these samples were unexpectedly high 
irrespective to their relatively low thrust force. Moreover, there is a strong tendency of chip clogging on the rake surface of the twist drill due to the discontinuous formation of chips during the drilling process along with the powdery and abrasive nature of the flax fiber composite laminates which is increased at a higher spindle speed, larger drill diameter and lower feed rate. Figure 9 shows the rake surface of the drill bit after drilling at a high spindle speed. Too much blockage on flank face of the cutting tool together with insufficient chip removal and lack of cooling between the composite laminate and drill, increased the drilling temperature. This resulted in delamination (cracks) propagation and surface damage. The results revealed that the thrust force and consequently the delamination tendency decreases slightly with an increase in spindle speed. However, the spindle speed should not be higher than the speeds that surpasses the composite melting point and melts the material. Also, tools wear out more quickly at higher spindle speeds which result in higher cutting thrust force and torque.

Higher spindle speeds will lead to lower forces, according on the general principle of high speed machining, and hence lesser delamination damage is predicted (Nassar, Arunachalam, and Alzebdeh 2016). The quality of the holes in sample 2, 4, 11 and 13 was observed to be in the acceptable range and only a few uncut fibers, fiber pull out and delamination were seen in these samples when compared with other samples. The lowest value of delamination factor (1.13) and the best hole appearance was seen in sample 11, and it is followed by sample 2, 4 and 13, respectively. This implies that the recommended machining condition for drilling Flax/PLA bi-composite in the range of parameters used is the spindle speed of $3000 \mathrm{rpm}$ and feed of $0.11 \mathrm{~mm} / \mathrm{rev}$. Figure 10 depicts the correlation between cutting force and delamination size of the drilled composite laminates. This result of the figure indicates that, while the measured delamination size in some drilling conditions seems to be independent of the thrust force, the general trend confirms the fact that increasing 
of thrust force results in damaging the matrix and fiber at the interfaces layer, which accordingly increases the delamination damage. Thus, this implies that the key to achieving better hole quality along with reducing the peripheral damage in drilling polymeric biocomposites relies on decreasing the drilling thrust force through proper selection of cutting parameters.

\section{Conclusion}

In this paper, an experimental study has been conducted to investigate the machinability associated with drilling unidirectional flax fiber/PLA bio-composite laminates. It intends to study the cutting parameters that affect cutting thrust force, delamination damage and the quality of the drilled holes, as well as establishing a correlation between them. A new thrust force measurement setup was developed and used in the research, which integrated piezoelectric load cell with fixtures, thus possesses the advantages of low cost, compact, and reconfigurable. Delamination factor is used to characterise the delamination damages in the hole-drilling process. ANOVA was applied to evaluate the relative importance of different drilling parameters.

Based on the results, the cutting thrust force, size of delamination and the defects occurrence rise considerably with the feed rate. When drilling a composite material using a twist drill bit, the combination of moderate diameter of the drill bit, lower feed rate, and higher spindle speed are the recommended setting of the operating variables to lessen delamination damage. The effect of the feed rate on the presence of delamination and propagation is established and the experimental results and ANOVA analysis confirmed that the higher feed rates correlate with the higher thrust force and drilling induced delamination. Machining processes have an effect on the structural integrity of NFRCs, thus, special attention should be given to selecting the appropriate combination of process parameters. The 
maximum delamination factor observed in the sample drilled with maximum feed rate and minimum spindle speed.

Since the thermal conductivity coefficient and transition temperature of polymeric composites are low, drilling these materials at very high cutting speed leads to a surge in the generated heat in the drilling area. The heat generation close to the drill edge can destroy the matrix stability, make thermal cuts and increase delamination and tool wear.

Thrust force is the main parameter responsible for delamination. The thrust force grows with the increase of the feed rate, and drill diameter, and decreases correspondingly when the spindle speed increases. Accompanied with thrust force, delamination size also grew by increasing the drill diameter and feed rate mainly because of enlarging the crosssectional area of the undeformed chip. Hence, controlling thrust force would be a considerable contribution toward delamination-free drilling which can improve the load carrying ability of composites.

\section{References:}

Abdul Nasir, A. A., A. I. Azmi, and A. N M Khalil. 2015. "Measurement and Optimisation of Residual Tensile Strength and Delamination Damage of Drilled Flax Fibre Reinforced Composites." Measurement: Journal of the International Measurement Confederation 75. Elsevier Ltd: 298-307. doi:10.1016/j.measurement.2015.07.046.

Abrão, A. M., J. C Campos Rubio, P. E. Faria, and J. P. Davim. 2008. "The Effect of Cutting Tool Geometry on Thrust Force and Delamination When Drilling Glass Fibre Reinforced Plastic Composite." Materials and Design 29 (2): 508-513. doi:10.1016/j.matdes.2007.01.016.

Alimuzzaman, Shah. 2013. "Nonwoven Flax Fibre Reinforced PLA Biodegradable Composites," 212. http://www.manchester.ac.uk/library.

Chegdani, F., S. Mezghani, M. El Mansori, and A. Mkaddem. 2015. "Fiber Type Effect on Tribological Behavior When Cutting Natural Fiber Reinforced Plastics." Wear 332-333. Elsevier: 772-779. doi:10.1016/j.wear.2014.12.039.

Chen, W. 1997. "Some Experimental Investigations in the Drilling of Carbon Fiber-Reinforced Plastic (CFRP) Composite Laminates." International Journal of Machine Tools and Manufacture 37 (8): 1097-1108. doi:10.1016/S0890-6955(96)00095-8.

Davim, J. Paulo, Pedro Reis, and C. Conceiçao António. 2004. "Experimental Study of Drilling Glass Fiber Reinforced Plastics (GFRP) Manufactured by Hand Lay-Up." Composites Science and Technology 64 (2): 289-297. doi:10.1016/S0266-3538(03)00253-7.

Fan, J., and J. Njuguna. 2016. An Introduction to Lightweight Composite Materials and Their Use in Transport Structures. Lightweight Composite Structures in Transport: Design, Manufacturing, Analysis and Performance. Elsevier Ltd. doi:10.1016/B978-1-78242-325-6.00001-3.

Faraz, A., D. Biermann, and K. Weinert. 2009. "Cutting Edge Rounding: An Innovative Tool Wear Criterion in Drilling CFRP Composite Laminates." International Journal of Machine Tools and Manufacture 49 (15). Elsevier: 1185-1196. doi:10.1016/j.ijmachtools.2009.08.002. 
Ho-Cheng, H., and C. K. H. Dharan. 1990. "Delamination During Drilling in Composite Laminates." Journal of Engineering for Industry 112 (3): 236. doi:10.1115/1.2899580.

Ho, Mei-po, H. Wang, J.H. Lee, C.K. Ho, K.T. Lau, J. Leng, and D. Hui. 2012. “Critical Factors on Manufacturing Processes of Natural Fibre Composites.” Composites Part B 8 (8). Elsevier Ltd: 3549-3562. doi:10.1016/j.compositesb.2011.10.001.

Hocheng, H., and C. C. Tsao. 2005. "The Path towards Delamination-Free Drilling of Composite Materials.” Journal of Materials Processing Technology 167 (2-3): 251-264. doi:10.1016/j.jmatprotec.2005.06.039.

Holbery, J, and D. Houston. 2006. "Natural-Fibre-Reinforced Polymer Composites in Automotive Applications." Journal of Minerals, Metals and Material Society 58 (11): 80-86.

Ismail, S. O., H. N. Dhakal, E. Dimla, J. Beaugrand, and I. Popov. 2016a. "Effects of Drilling Parameters and Aspect Ratios on Delamination and Surface Roughness of Lignocellulosic HFRP Composite Laminates." Journal of Applied Polymer Science 133 (7). doi:10.1002/app.42879.

Ismail, S. O., H. N. Dhakal, E. Dimla, J. Beaugrand, and I. Popov. 2016b. "Effects of Drilling Parameters and Aspect Ratios on Delamination and Surface Roughness of Lignocellulosic HFRP Composite Laminates.” Journal of Applied Polymer Science 133 (7): 1-8. doi:10.1002/app.42879.

Kavad, B.V., A.B. Pandey, M.V. Tadavi, and H.C. Jakharia. 2014. "A Review Paper on Effects of Drilling on Glass Fiber Reinforced Plastic." Procedia Technology 14. Elsevier B.V.: 457-464. doi:10.1016/j.protcy.2014.08.058.

Khashaba, U. A., I. A. El-Sonbaty, A. I. Selmy, and A. A. Megahed. 2010. "Machinability Analysis in Drilling Woven GFR/Epoxy Composites: Part II - Effect of Drill Wear." Composites Part A: Applied Science and Manufacturing 41 (9). Elsevier Ltd: 1130-1137. doi:10.1016/j.compositesa.2010.04.011.

Kwon, H. J., J. Sunthornvarabhas, J.W. Park, J. H. Lee, H. J. Kim, K. Piyachomkwan, K. Sriroth, and D. Cho. 2014. "Tensile Properties of Kenaf Fiber and Corn Husk Flour Reinforced Poly(Lactic Acid) Hybrid Bio-Composites: Role of Aspect Ratio of Natural Fibers." Composites Part B: Engineering 56. Elsevier Ltd: 232-237. doi:10.1016/j.compositesb.2013.08.003.

Mazumder, P., Y H K Reddy, M. P. Borsaikia, and S. Kashyap. 2016. “Optimization of process parameters in drilling of bamboo fibre reinforced polymeric composites." International Journal of Science Technology and Managment 5 (5): 422-434.

Nassar, M. M. A., R. Arunachalam, and K. I. Alzebdeh. 2016. "Machinability of Natural Fiber Reinforced Composites: A Review." The International Journal of Advanced Manufacturing Technology. The International Journal of Advanced Manufacturing Technology. doi:10.1007/s00170-016-9010-9.

Nirmal, U., K. O. Low, and J. Hashim. 2012. "On the Effect of Abrasiveness to Process Equipment Using Betelnut and Glass Fibres Reinforced Polyester Composites." Wear 290-291. Elsevier: 32-40. doi:10.1016/j.wear.2012.05.022.

Pil, L., F. Bensadoun, J. Pariset, and I. Verpoest. 2016. "Why Are Designers Fascinated by Flax and Hemp Fibre Composites?” Composites Part A: Applied Science and Manufacturing 83. Elsevier Ltd: 193-205. doi:10.1016/j.compositesa.2015.11.004.

Pradeep K. J., P. Packiaraj. 2012. "Effect of Drilling Parameter on Surface Roughness, Tool Wear, Material, Material Removal Rate and Hole Diameter Errot in Drilling of Ohns." International Journal of Advanced Engineering Research and Studies 2249-8974: 150-154.

Rawat, S., and H. Attia. 2009. "Wear Mechanisms and Tool Life Management of WC-Co Drills during Dry High Speed Drilling of Woven Carbon Fibre Composites.” Wear 267 (5-8): 10221030. doi:10.1016/j.wear.2009.01.031.

Saleem, M., L. Toubal, R. Zitoune, and H. Bougherara. 2013. "Investigating the Effect of Machining Processes on the Mechanical Behavior of Composite Plates with Circular Holes." Composites Part A: Applied Science and Manufacturing 55. Elsevier Ltd: 169-177. doi:10.1016/j.compositesa.2013.09.002.

Singh, I., N. Bhatnagar, and P. Viswanath. 2008. "Drilling of Uni-Directional Glass Fiber Reinforced Plastics: Experimental and Finite Element Study.” Materials and Design 29 (2): 546-553. 
doi:10.1016/j.matdes.2007.01.029.

Sreenivasulu, R., and C. Srinivasa Rao. 2016. "Effect of drilling parameters on thrust force and torque during drilling of aluminium 6061 alloy - based on taguchi design of experiments" $\mathrm{M}$ (December): 41-48.

Sunny, T., J. Babu, and J., Philip. 2014. "Experimental Studies on Effect of Process Parameters on Delamination in Drilling GFRP Composites Using Taguchi Method." Procedia Materials Science 6 (Icmpc). Elsevier B.V.: 1131-1142. doi:10.1016/j.mspro.2014.07.185.

Tsao, C. C., and H. Hocheng. 2004. "Taguchi Analysis of Delamination Associated with Various Drill Bits in Drilling of Composite Material." International Journal of Machine Tools and Manufacture 44 (10): 1085-1090. doi:10.1016/j.ijmachtools.2004.02.019.

Turki, Y., M. Habak, R. Velasco, Z. Aboura, K. Khellil, and P. Vantomme. 2014. "Experimental Investigation of Drilling Damage and Stitching Effects on the Mechanical Behavior of Carbon/Epoxy Composites." International Journal of Machine Tools and Manufacture 87. Elsevier: 61-72. doi:10.1016/j.ijmachtools.2014.06.004.

Velayudham, A., and R. Krishnamurthy. 2007. "Effect of Point Geometry and Their Influence on Thrust and Delamination in Drilling of Polymeric Composites." Journal of Materials Processing Technology 185 (1-3): 204-209. doi:10.1016/j.jmatprotec.2006.03.146. 


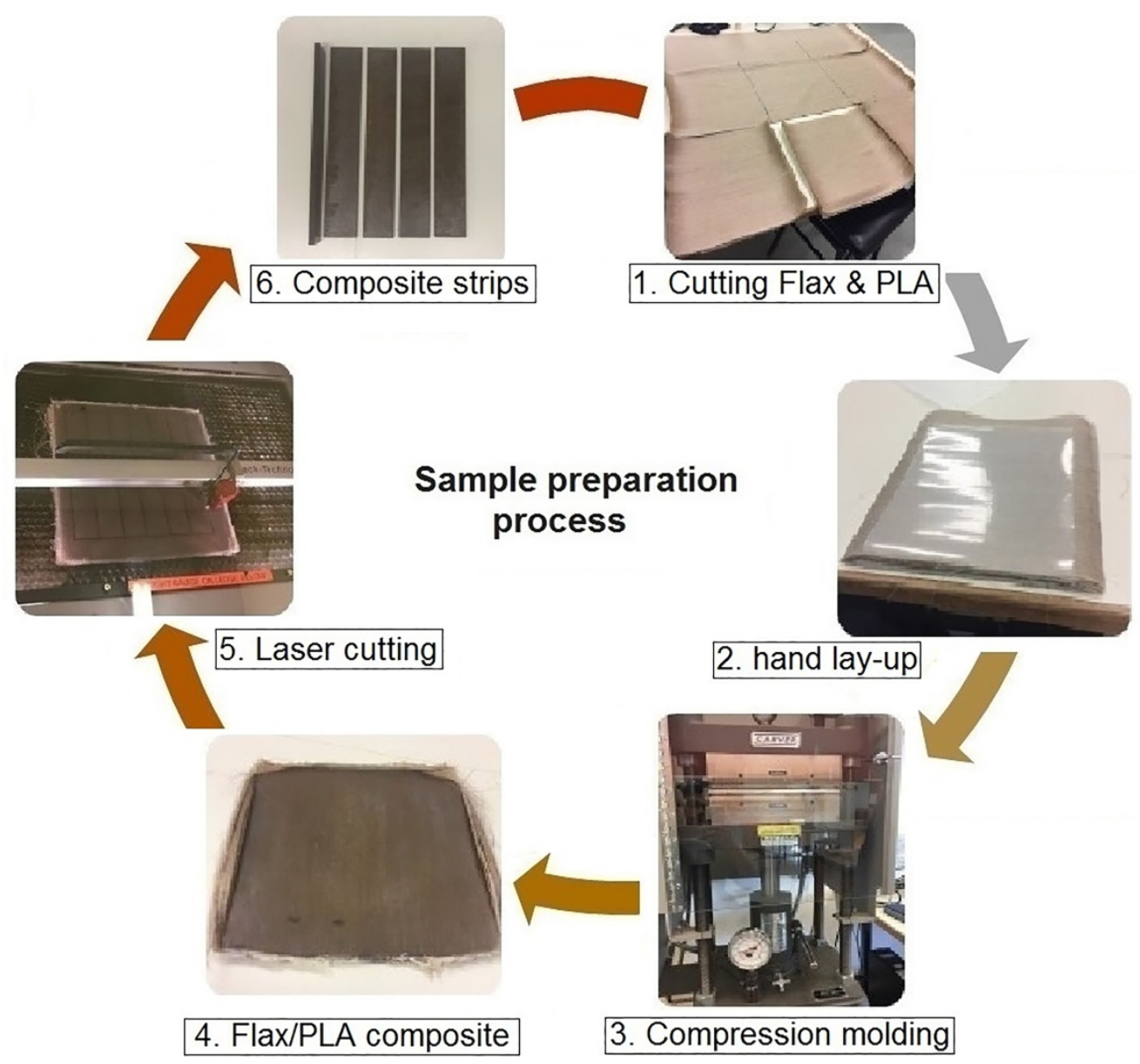

Figure 1. Fabrication process of composite samples for drilling $206 \times 190 \mathrm{~mm}(300 \times 300 \mathrm{DPI})$ 
Figure 2. Schematic of the experimental set-up

$122 \times 34 \mathrm{~mm}(300 \times 300$ DPI $)$ 

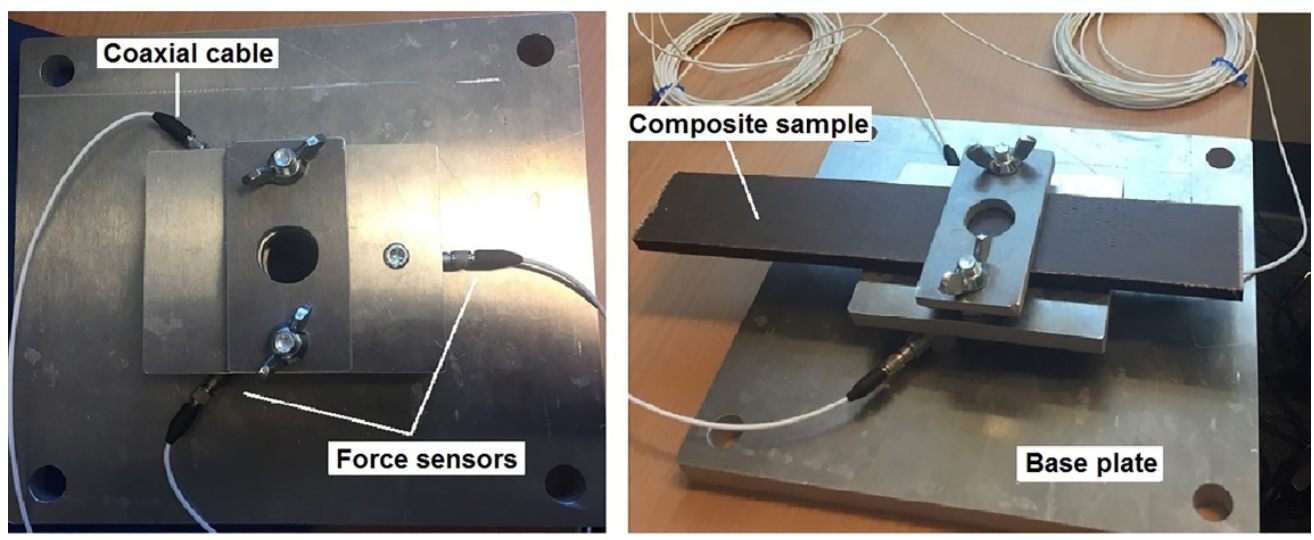

Figure 3. Drilling sample holder and set-up for measurements the thrust force $284 \times 214 \mathrm{~mm}(300 \times 300 \mathrm{DPI})$ 

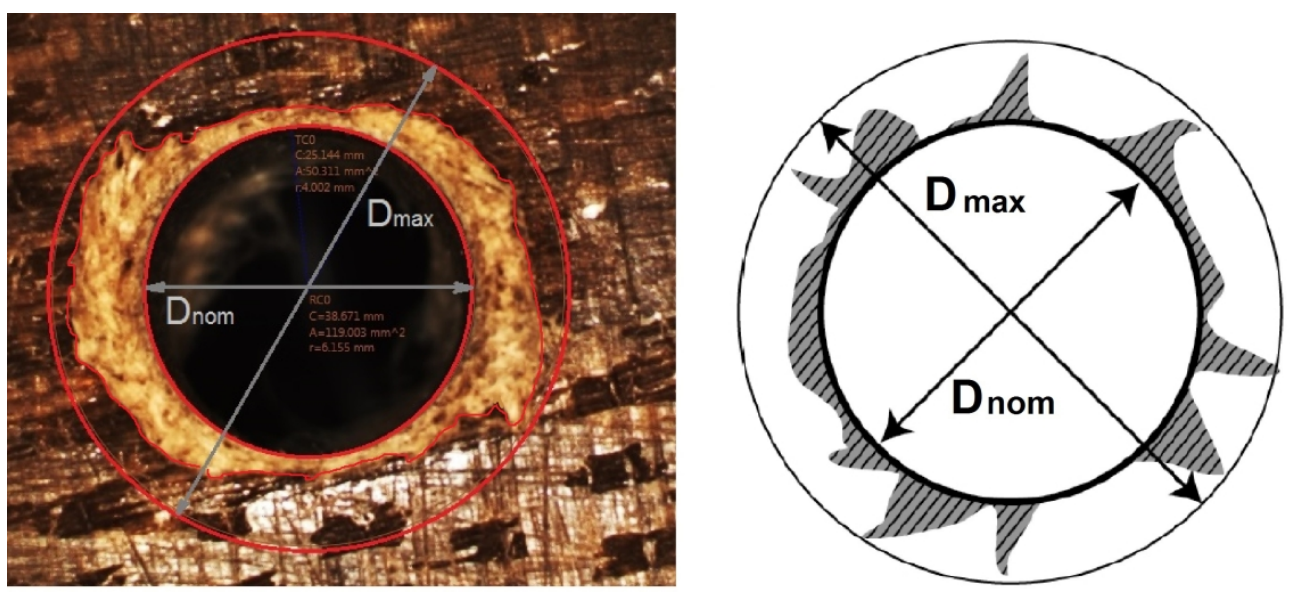

Figure 4. Scheme of evaluation of one-dimensional delamination factor 


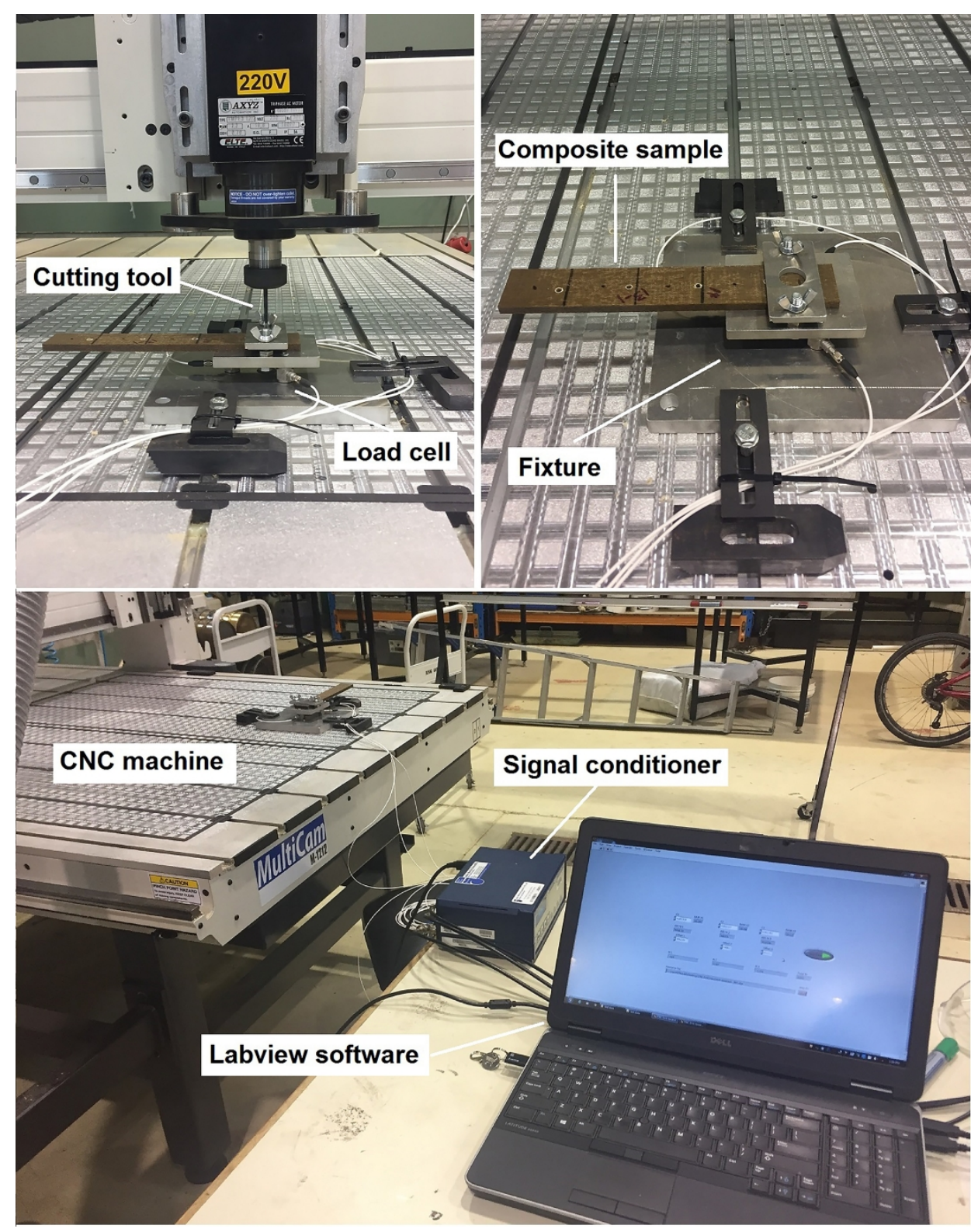

Figure 5. Drilling set-up overview $296 \times 376 \mathrm{~mm}(300 \times 300 \mathrm{DPI})$ 

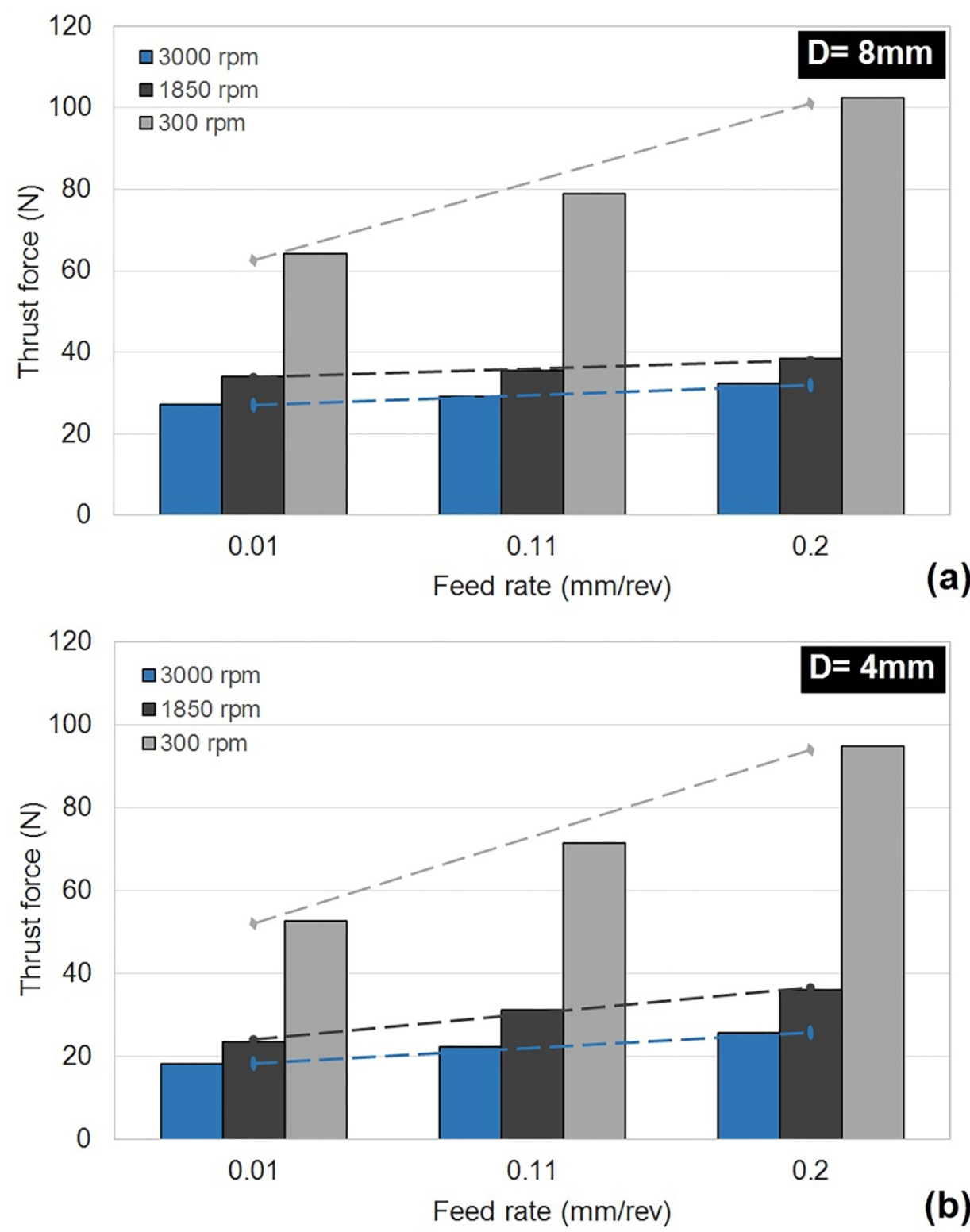

Figure 6. Effect of feed rate and spindle speed on thrust force when drilling FF/PLA composite samples using (a) $8 \mathrm{~mm}$, and (b) $4 \mathrm{~mm}$ drills $209 \times 262 \mathrm{~mm}(300 \times 300 \mathrm{DPI})$ 


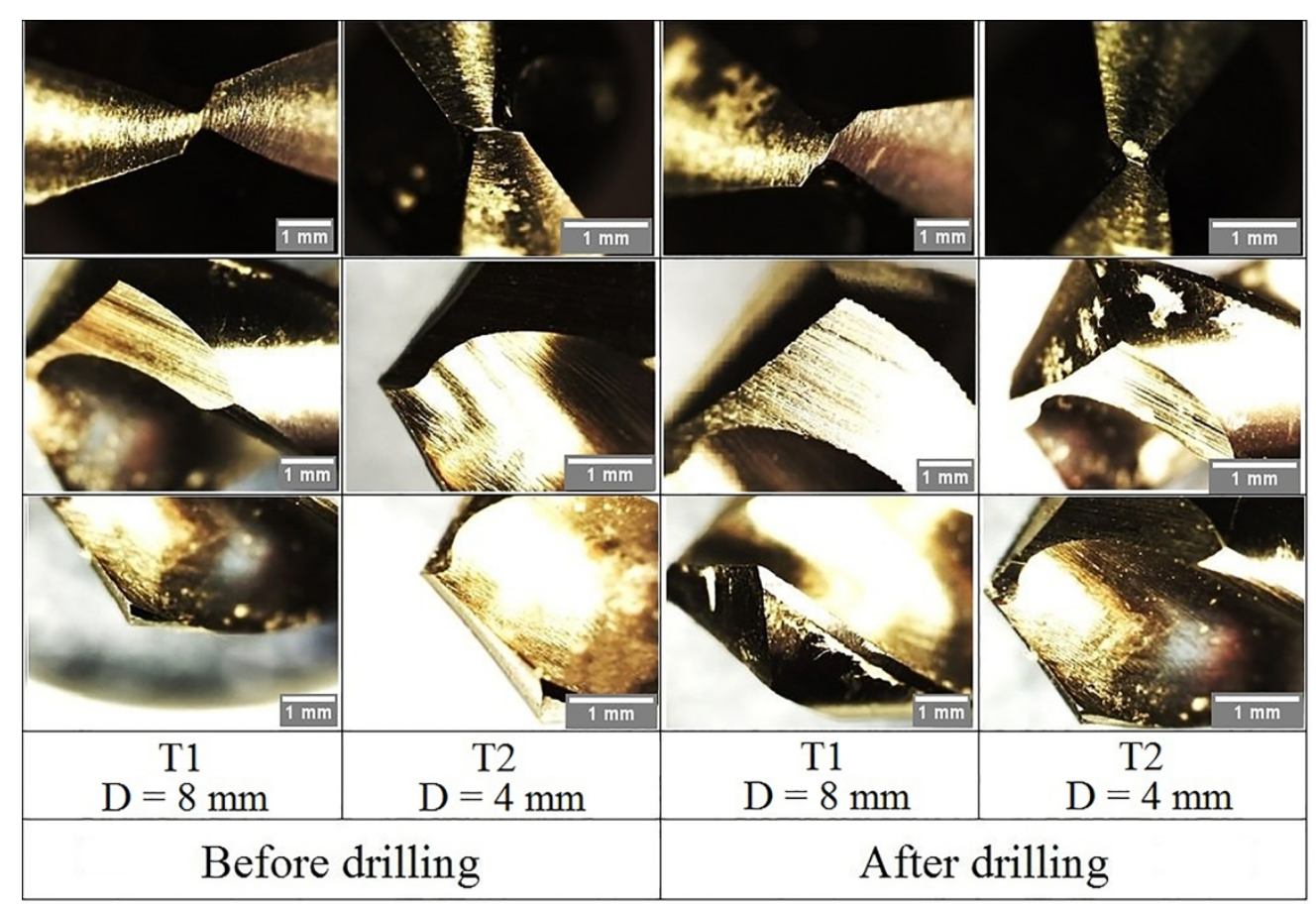

Figure 7. Tools condition before and after the drilling operation 


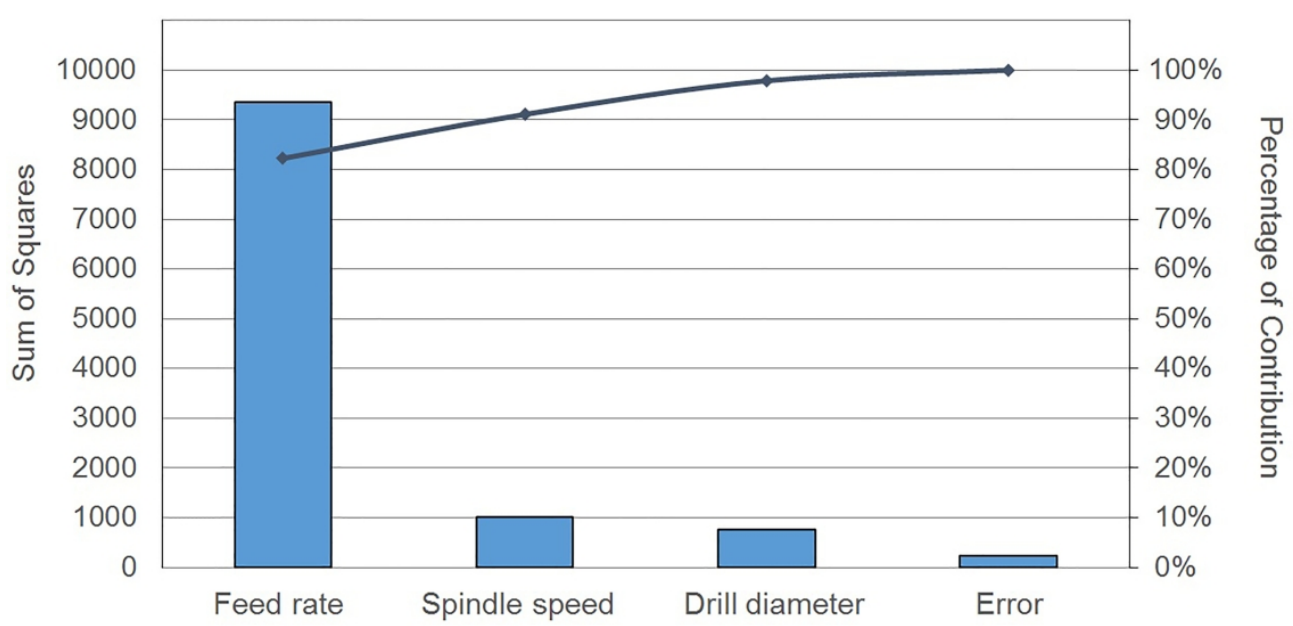

Figure 8. The Pareto chart of cutting factors

$263 \times 130 \mathrm{~mm}(300 \times 300 \mathrm{DPI})$ 


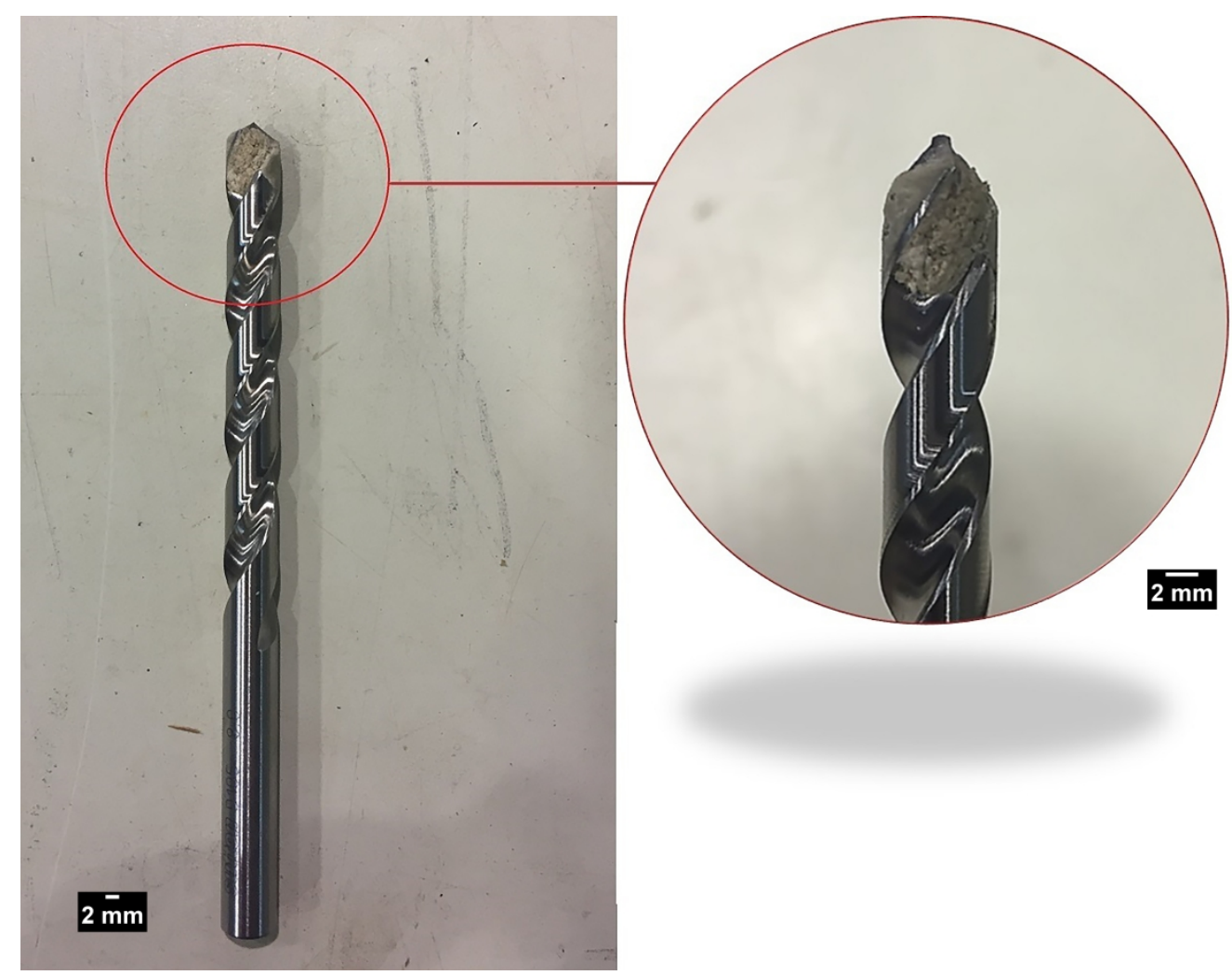

Figure 9. Melted composite on the rake surface of the drill bit 

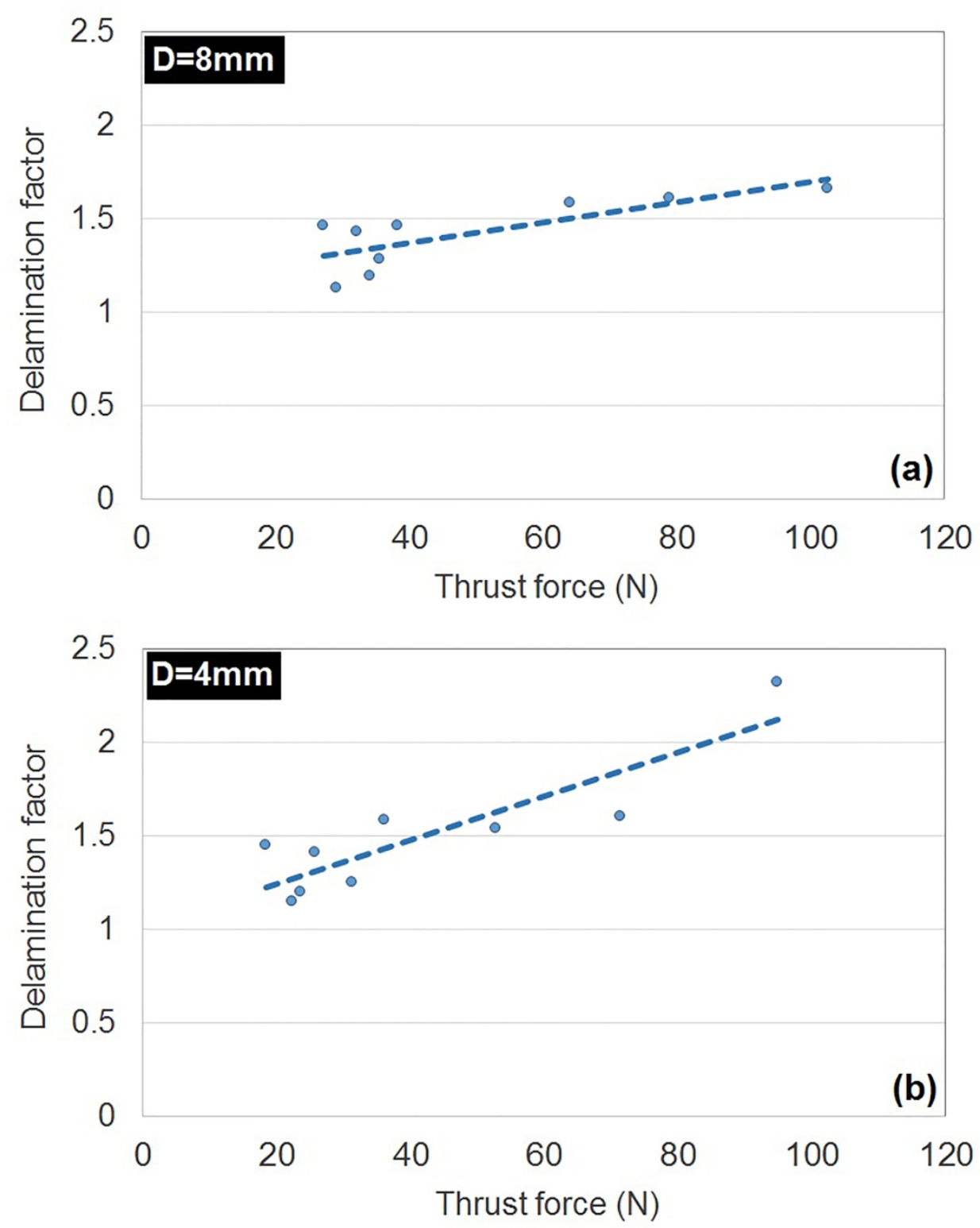

Figure 10. Correlation between drilling thrust force and delamination size using (a) $8 \mathrm{~mm}$, and (b) $4 \mathrm{~mm}$ drills $174 \times 219 \mathrm{~mm}(300 \times 300 \mathrm{DPI})$ 
Table 1. Twist Drills Specification

\begin{tabular}{|c|c|c|c|c|}
\hline Set & $\begin{array}{l}\text { Diameter } \\
(\mathrm{mm})\end{array}$ & $\begin{array}{l}\text { Length } \\
(\mathrm{mm})\end{array}$ & Description & 1 \\
\hline 1 & 8 & 116.30 & $\begin{array}{l}\text { Twist drills, two helical cutting } \\
\text { lips, different diameters, point }\end{array}$ & 2 \\
\hline 2 & 4 & 75.64 & $\begin{array}{l}\text { angle } 118^{\circ}, \text { high speed steel } \\
\text { (HSS) made by Sutton tools }\end{array}$ & $x \rightarrow x \Rightarrow 2=$ \\
\hline
\end{tabular}


Table 2. Experimental Layout plan

\begin{tabular}{cccc}
\hline $\begin{array}{c}\text { Test } \\
\text { No. }\end{array}$ & $\begin{array}{c}\text { Spindle speed } \\
(\mathrm{rpm})\end{array}$ & $\begin{array}{c}\text { Feed rate } \\
(\mathrm{mm} / \mathrm{rev})\end{array}$ & $\begin{array}{c}\text { Drill } \\
\text { diameter } \\
(\mathrm{mm})\end{array}$ \\
\hline 1 & 3000 & 0.01 & 8 \\
2 & 3000 & 0.11 & 8 \\
3 & 3000 & 0.20 & 8 \\
4 & 1850 & 0.01 & 8 \\
5 & 1850 & 0.11 & 8 \\
6 & 1850 & 0.20 & 8 \\
7 & 300 & 0.01 & 8 \\
8 & 300 & 0.11 & 8 \\
9 & 300 & 0.20 & 8 \\
10 & 3000 & 0.01 & 4 \\
11 & 3000 & 0.11 & 4 \\
12 & 3000 & 0.20 & 4 \\
13 & 1850 & 0.01 & 4 \\
14 & 1850 & 0.11 & 4 \\
15 & 1850 & 0.20 & 4 \\
16 & 300 & 0.01 & 4 \\
17 & 300 & 0.11 & 4 \\
18 & 300 & 0.20 & 4 \\
\hline
\end{tabular}


Table 3. Top and bottom surface of drilled specimens with different drilling conditions

\begin{tabular}{|c|c|c|c|c|c|c|}
\hline $\begin{array}{l}\text { Test } \\
\text { No. }\end{array}$ & $\begin{array}{l}\text { Drill Entrance } \\
\text { (Peel-up) }\end{array}$ & $\begin{array}{c}\text { Drill Exit } \\
\text { (Push-down) }\end{array}$ & $\begin{array}{c}\text { Drilling } \\
\text { Condition } \\
\end{array}$ & $\begin{array}{c}\text { Thrust } \\
\text { Force }(\mathrm{N})\end{array}$ & $\begin{array}{c}\text { Delamination } \\
\text { Factor, } \mathrm{F}_{\mathrm{d}}\end{array}$ & $\begin{array}{c}\text { MRR } \\
\left(\mathrm{mm}^{3} / \mathrm{min}\right)\end{array}$ \\
\hline 1 & & & $\begin{array}{l}\mathrm{N}=3000 \mathrm{rpm} \\
\mathrm{F}=0.01 \mathrm{~mm} / \mathrm{rev} \\
\mathrm{D}=8 \mathrm{~mm}\end{array}$ & 27 & 1.46 & 1507 \\
\hline 2 & & & $\begin{array}{l}\mathrm{N}=3000 \mathrm{rpm} \\
\mathrm{F}=0.11 \mathrm{~mm} / \mathrm{rev} \\
\mathrm{D}=8 \mathrm{~mm}\end{array}$ & 29 & 1.15 & 16579 \\
\hline 3 & & & $\begin{array}{l}\mathrm{N}=3000 \mathrm{rpm} \\
\mathrm{F}=0.20 \mathrm{~mm} / \mathrm{rev} \\
\mathrm{D}=8 \mathrm{~mm}\end{array}$ & 32 & 1.53 & 30144 \\
\hline 4 & & & $\begin{array}{l}\mathrm{N}=1850 \mathrm{rpm} \\
\mathrm{F}=0.01 \mathrm{~mm} / \mathrm{rev} \\
\mathrm{D}=8 \mathrm{~mm}\end{array}$ & 34 & 1.19 & 929 \\
\hline 5 & & & $\begin{array}{l}\mathrm{N}=1850 \mathrm{rpm} \\
\mathrm{F}=0.11 \mathrm{~mm} / \mathrm{rev} \\
\mathrm{D}=8 \mathrm{~mm}\end{array}$ & 36 & 1.28 & 10224 \\
\hline 6 & & & $\begin{array}{l}\mathrm{N}=1850 \mathrm{rpm} \\
\mathrm{F}=0.20 \mathrm{~mm} / \mathrm{rev} \\
\mathrm{D}=8 \mathrm{~mm}\end{array}$ & 38 & 1.46 & 18589 \\
\hline 7 & & & $\begin{array}{l}\mathrm{N}=300 \mathrm{rpm} \\
\mathrm{F}=0.01 \mathrm{~mm} / \mathrm{rev} \\
\mathrm{D}=8 \mathrm{~mm}\end{array}$ & 64 & 1.58 & 151 \\
\hline 8 & & & $\begin{array}{l}\mathrm{N}=300 \mathrm{rpm} \\
\mathrm{F}=0.11 \mathrm{~mm} / \mathrm{rev} \\
\mathrm{D}=8 \mathrm{~mm}\end{array}$ & 79 & 1.61 & 1658 \\
\hline 9 & & & $\begin{array}{l}\mathrm{N}=300 \mathrm{rpm} \\
\mathrm{F}=0.20 \mathrm{~mm} / \mathrm{rev} \\
\mathrm{D}=8 \mathrm{~mm}\end{array}$ & 103 & 1.66 & 3014 \\
\hline 10 & & & $\begin{array}{l}\mathrm{N}=3000 \mathrm{rpm} \\
\mathrm{F}=0.01 \mathrm{~mm} / \mathrm{rev}\end{array}$ & 18 & 1.45 & 377 \\
\hline 11 & & & $\begin{array}{l}\mathrm{N}=3000 \mathrm{rpm} \\
\mathrm{F}=0.11 \mathrm{~mm} / \mathrm{rev} \\
\mathrm{D}=4 \mathrm{~mm}\end{array}$ & 22 & 1.13 & 4145 \\
\hline 12 & $602 \frac{1}{14}$ & it & $\begin{array}{l}\mathrm{N}=3000 \mathrm{rpm} \\
\mathrm{F}=0.20 \mathrm{~mm} / \mathrm{rev} \\
\mathrm{D}=4 \mathrm{~mm}\end{array}$ & 26 & 1.41 & 7536 \\
\hline 13 & Ex) & $\frac{1}{2}$ & $\begin{array}{l}\mathrm{N}=1850 \mathrm{rpm} \\
\mathrm{F}=0.01 \mathrm{~mm} / \mathrm{rev} \\
\mathrm{D}=4 \mathrm{~mm}\end{array}$ & 24 & 1.20 & 232 \\
\hline
\end{tabular}




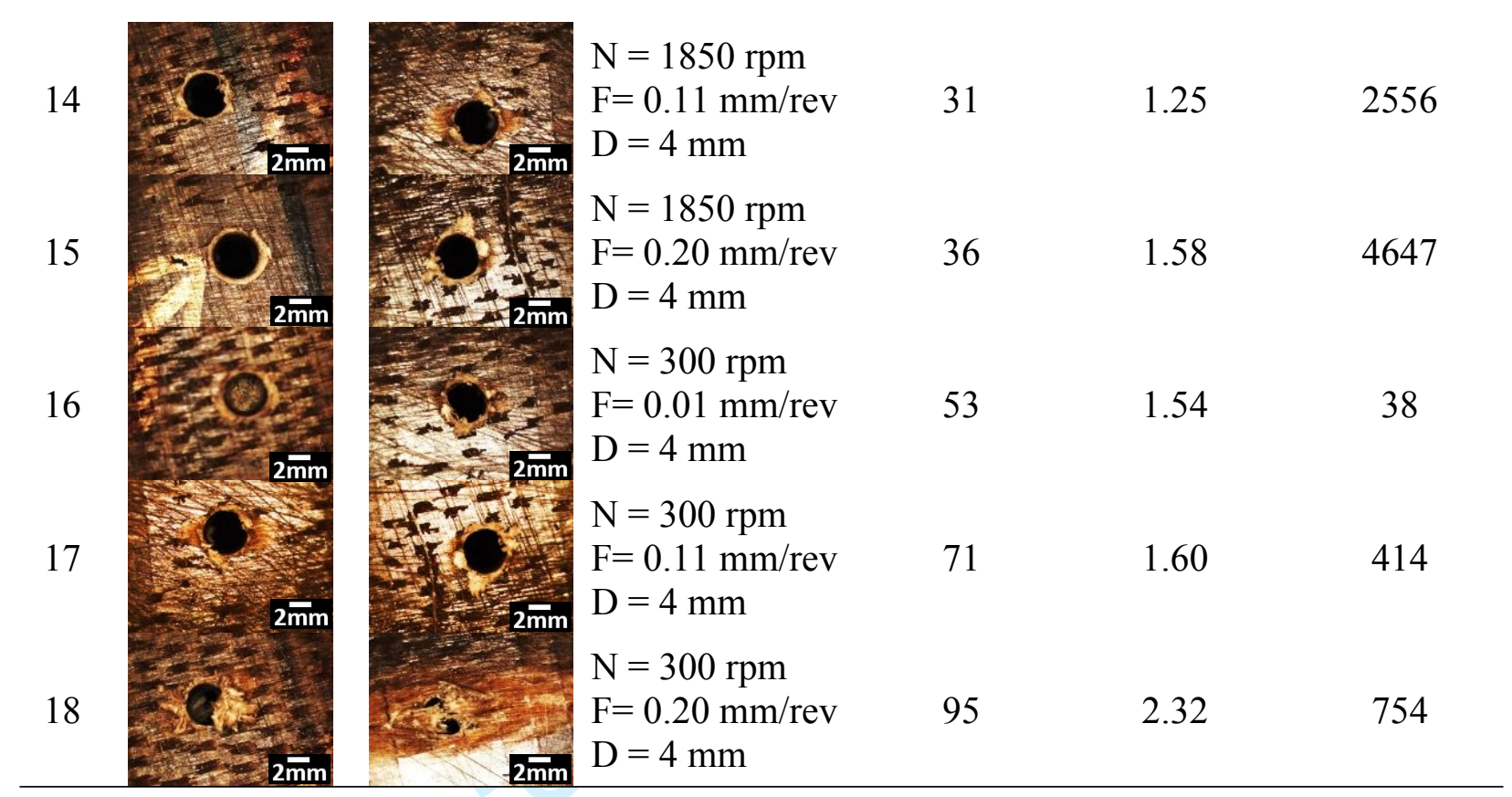


Table 4. Analysis of variance for thrust force in drilling

\begin{tabular}{cccccc}
\hline Source & Sum of Squares & Degrees of Freedom & Mean Square & F Value & P-Value \\
\hline Spindle speed & 1005.42 & 2 & 502.71 & 7.85 & 0.0066 \\
Feed rate & 9349.29 & 2 & 4674.64 & 72.99 & 0.0001 \\
Drill diameter & 768.55 & 1 & 239.84 & 3.74 & 0.0769 \\
Error & 239.81 & 12 & 64.05 & & \\
Total & 11363.07 & 17 & & & \\
\hline
\end{tabular}




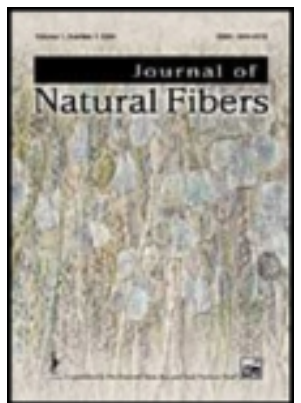

\section{Drilling behavior of flax/poly(lactic acid) bio-composite laminates: An experimental investigation}

\begin{tabular}{|r|l|}
\hline Journal: & Journal of Natural Fibers \\
\hline Manuscript ID & WJNF-2018-0304.R1 \\
\hline Manuscript Type: & Original Article \\
\hline Keywords: & $\begin{array}{l}\text { Natural fiber reinforced composites, thrust force, delamination, drilling, } \\
\text { machinability, composite }\end{array}$ \\
\hline \multicolumn{2}{|l}{} \\
\hline
\end{tabular}

\section{SCHOLARONE \\ Manuscripts}

